\title{
Alain Mabanckou, Le monde est mon langage
}

\section{Carminella Biondi}

\section{(2) OpenEdition}

\section{Journals}

\section{Édition électronique}

URL : http://journals.openedition.org/studifrancesi/10621

DOI : 10.4000/studifrancesi. 10621

ISSN : 2427-5856

\section{Éditeur}

Rosenberg \& Sellier

\section{Édition imprimée}

Date de publication : 1 décembre 2017

Pagination : 594-595

ISSN : 0039-2944

\section{Référence électronique}

Carminella Biondi, « Alain Mabanckou, Le monde est mon langage », Studi Francesi [En ligne], 183 (LXI |

III) | 2017, mis en ligne le 01 février 2018, consulté le 21 janvier 2021. URL : http://

journals.openedition.org/studifrancesi/10621 ; DOI : https://doi.org/10.4000/studifrancesi.10621

\section{Ce document a été généré automatiquement le 21 janvier 2021.}

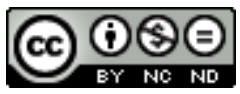

Studi Francesi è distribuita con Licenza Creative Commons Attribuzione - Non commerciale - Non opere derivate 4.0 Internazionale. 


\title{
Alain Mabanckou, Le monde est mon langage
}

\author{
Carminella Biondi
}

\section{RÉFÉRENCE}

ALAIN MABANCKOU, Le monde est mon langage, Paris, Grasset, 2016, 318 pp.

1 La jaquette du livre reproduit l'image de l'écrivain qui porte sur son épaule, en un demi-cercle parfait, le titre de son ouvrage. C'est une image qui fixe l'attention du lecteur et qui dit, dans une synthèse parfaite, l'essence du livre: l'écrivain, qui nous regarde dans les yeux, nous invite à le suivre dans son voyage à travers le monde qui est le sien, où se rencontrent trois continents: l'Afrique, l'Europe et l'Amérique. C'est le monde noir de langue française, et en particulier de la diaspora noire, qui dialogue pourtant, à la guise du Tout-monde glissantien, avec tant de voix qui ont croisé son chemin, qui l'ont nourri ou s'en sont nourries. Le livre trace un panorama ample et mouvant de l'écriture noire, qui suit les pérégrinations de l'auteur, mais qui nous dit aussi la mouvance de notre époque où tant d'écrivains sont «multiples», vivant, ou ayant vécu, loin de leur lieu de naissance et souvent sans un lieu d'ancrage certain, dans une mobilité toujours problématique, mais qui permet de respirer le monde, de le voir au-delà de cet enfermement identitaire qui bloque souvent les écrivains bien enracinés.

2 La langue de Mabanckou, écrivain congolais, est le français, mais son langage est justement celui du monde dont il dénombre les accents dans ce volume qui est en même temps un recueil d'essais et un parcours autobiographique, dont les étapes sont une série de chapitres qui renvoient à autant de lieux: les lieux de naissance, de séjour ou de passage d'un ou de plusieurs écrivains qu'il a croisés, interviewés, ou tout simplement lus au cours des années. Le choix du lieu comme point d'ancrage de l'essai est important, car, pour le dire avec Glissant, «le lieu est incontournable», c'est de là qu'il faut partir pour comprendre. C'est donc de «Pointe-Noire», la ville sur l'Atlantique 
où Mabanckou est né, que nous partirons, même si c'est l'un des derniers chapitres du volume (pp. 277-286). Selon Mabanckou, Pointe-Noire était «l'une des métropoles» qui symbolisait l'éveil de l'Afrique, une ville ouverte: «Les Ponténégrins, eux, étaient au carrefour du monde» (p. 281). C'est peut-être là l'origine d'une vocation que la vie n'a fait que confirmer. Dans le chapitre intitulé «Madagascar» (pp. 219-231), où Mabanckou se penche sur les deux grands écrivains francophones de l'île, Jean-Joseph Rabearivelo et Jacques Rabemananjara, il nous dit aussi, indirectement, le but qu'il poursuit dans ce livre. Rabemananjara, dans sa préface à un recueil poétique de Rabearivelo, définit celui-ci comme un écrivain qui a su rompre les barrières, pour «s'apparenter au rythme chaud des énergies cosmiques» (p. 229). Je crois que c'est justement ce rythme que Mabanckou cherche dans les écrivains qu'il a choisi de nous présenter car, comme tant d'intellectuels issus des terres de colonisation et d'esclavage, il est en quête de ce qui unit les hommes et non de ce qui les sépare.

Le volume se compose de vingt et un chapitres, suivis d'un «Post-scriptum» qui en comporte trois autres, très brefs, qui ne sont pas focalisés sur un lieu: «Le monde sur une île déserte», (pp. 301-303), qui présente les trois livres qu'il voudrait avoir comme compagnons sur l'île (Le Livre de ma mère d'Albert Cohen, Des souris et des hommes de John Steinbeck et Pas de lettre pour le colonel de Gabriel García Marquez); «Une littérature afropolitaine?» (pp.305-310), où il conteste la nouveauté de l'étiquette et reconnaît à la France «d'être et de demeurer une nation littéraire» (p. 309), et «Moi aussi je suis l'Amérique» (pp. 311-315), où il pose le problème des rapports raciaux dans un pays qui a été bâti "par des mains de toutes les couleurs...» (p. 313). Le recueil s'ouvre et se ferme sur Paris, pour signifier, je crois par un choix voulu, que la France est encore le lieu où tant des forces se croisent, mais il s'agit toutefois déjà d'une «France autre», car le premier chapitre («Paris», pp. 17-34) est consacré à l'écrivain d'origine mauricienne, Le Clézio, un écrivain qui porte en lui le «souffle du monde» (p. 21) et le dernier, ainsi que l'indique le titre, «Château-rouge» (pp. 287-297), est situé dans le quartier le plus africain de Paris et le personnage le plus important est tel «Jocelyn le Bachelor», qui est une «figure emblématique du milieu de la Sape (Société des ambianceurs et des personnes élégantes), mouvement né au Congo, qui se caractérise par un habillement à la fois étudié et ostentatoire» (p. 293). Un phénomène, celui de la Sape, étudié par les sociologues, qui a fait des prosélytes en Europe, en Amérique, au Japon... Tout se mélange, les lieux aussi bien que les hommes, de n'importe quel état: ainsi le clochard de la «Nouvelle-Orléans» (pp. 35-50), Zéphirin Métellus, qui se veut descendant de Toussaint Louverture et qui n'est pas écrivain, trouve l'expression la plus poétique pour dire la difficulté d'être: «Je ne sais plus quel train emprunter pour arriver jusqu'à la gare de la vie» (pp. 45-46).

4 Les chapitres se suivent: «Sainte-Marie (Martinique)» (pp. 51-65), sur Glissant, dont le grand souffle novateur parcourt le recueil, et «Montréal» (pp. 67-84) sur Dany Laferrière, et «Londres» (pp. 87-97) sur Conrad, le seul écrivain d'origine européenne qui entre dans le recueil, à cause, évidemment, de son roman Au cœur des ténèbres (1899), qui a suscité tant de réactions, parfois négatives, de la part des intellectuels africains. Les plus nombreux sont les chapitres sur l'Afrique et les écrivains (écrivaines) africains: «Makélékélé (Brazzavile)», «Alger», «Le Caire», «Mpili (Congo)», «Douala», «Marrakech», «Dakar», «Brazzaville»..., avec les grands écrivains qui y vivent ou y ont vécu et ont posé les fondements du renouveau culturel d'un continent, qui a pourtant du mal à démarrer: Sony Labou Tansi, Tchicaya U Tam'si, Camara Laye, Henri Lopes, Ahmadou Kourouma, Kateb Yacine, Rachid Boudjedra, Rachid, Mimouni, Assia Djebar, 
Malika Mokeddem, Maïssa Bey, Bessora... Les grands écrivains africains de langue anglaise entrent aussi en jeu, car la différence de langue n'oppose aucune barrière au langage du monde: Chinua Achebe, Wole Soyinka, Nadine Gordimer, J. M. Coetzee, et tant d'autres, pour conclure avec une jeune écrivaine nigériane, que Mabanckou définit comme la romancière africaine la plus brillante: Chimanda Ngozi Adichie, qui vit entre le Nigéria et les États-Unis, ainsi qu'il se convient à un écrivain du «Tout-monde». Et il y a encore les Antilles: Cuba (Eduardo Manet), La Martinique (Patrick Chamoiseau), Haïti (Gay Victor).

5 L'auteur définit le livre comme une «autobiographie capricieuse». Elle est aussi une séduisante invitation au voyage dans le monde des livres «déracinés», où l'imaginaire, «aussi bariolé que l'arc-en-ciel», nous pousse à «nous remettre en question». 